\title{
EXERCÍCIO DA DÚVIDA NO TRABALHO INTERDISCIPLINAR
}

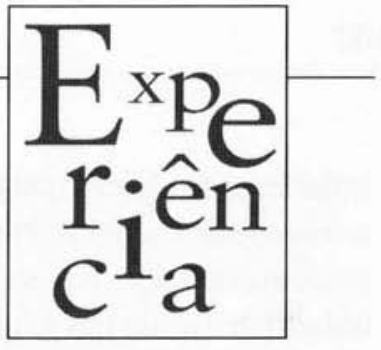

\section{Com o apoio de jornais, da literatura e da observação direta do meio ambiente, professoras desenvolvem atividades interdisciplinares no ensino fundamental}

"Encontrei o trabalho pedagógico das professoras em construção. Havia um desejo de romper com o estabelecido, o parâmetro curricular já institucionalizado. Isto ficou muito claro pela relação dialógica que a professora mantinha com os alunos. Não é sem razão que tal relação desencadeou um interesse pela busca de uma forma de ensino que estivesse dentro das vidas de seus alunos, relativa a eles, ou seja, um tema que fora o dínamo para uma empreitada de estudo surgia a partir dos diálogos estabelecidos entre educadora e educandos (...)" Alexandre Filordi, estagiário do Curso de Pedagogia da Faculdade de Educação da Unicamp.

Desde que começamos a exercer a profissão de professoras no ensino público do Estado de São Paulo, há quase dez anos, buscávamos uma metodologia para o ensino de Ciências que estabelecesse uma relação dialógica com o aluno. A proposta que vamos apresentar neste artigo e que concretiza nossas intenções partiu de uma sugestão da Prof ${ }^{\text {a }}$. Mariley Simões Flória Gouveia, em 1997, enquanto éramos alunas do Curso de Especialização em avaliação escolar e ensino nas séries iniciais do ensino fundamental, sob a coordenação do Laboratório de Observação e Estudos Descritivos (LOED)/Unicamp.

A nossa proposta pedagógica para o ensino de Ciências, com alunos de terceiras e quartas séries do ensino fundamental, centrou-se no estudo do calendário através da análise da variação diária da temperatura ambiente, que passamos a denominar como um subtema do tema $o$ ambiente.

Entendemos que $o$ ambiente deva ser considerado como propõe Amaral neste trecho: "O ambiente terrestre, entendido em todos os seus aspectos, naturais e artificiais, será a matéria-prima geradora da lista

\section{AS AUTORAS}

Antônia Aparecida Justti

Professora do Ensino Fundamental da Escola Estadual Benedita Wagner de Campos, Indaiatuba - São Paulo.

Sílvia Lúcia Silva Pinto Professora do Ensino Fundamental da Escola Estadual Benedita Wagner de Campos, Indaiatuba - São Paulo. 
infindável de tópicos que poderão ser escolhidos como conteúdo curricular no ensino de Ciências. Porém, funcionará como elemento unificador deste mesmo conteúdo, na medida em que cada ser ou fenômeno estudado for tratado de forma integrada, no contexto de outros seres ou fenômenos a ele relacionados. Para assim proceder, será recomendável trabalhar, em cada caso, as múltiplas relações entre os macro-constituintes do ambiente (hidrosfera, atmosfera, litosfera, biosfera, Terra como um todo) e seus determinantes (matéria, energia, transformações e interações*),...tomadas nas diferentes escalas espaço-temporais possíveis e significativas"' .

$\mathrm{O}$ ambiente, tomado como elemento unificador de conteúdos, possibilita uma abordagem interdisciplinar, segundo Gouveia: "Ao estudarmos o subtema chão, ou outro qualquer [dentro do tema ambiente], numa abordagem interdisciplinar, devemos estabelecer as conexões entre os diferentes campos do conhecimento. Os assuntos (chão, seres vivos e estações do ano) podem ser abordados interdisciplinarmente quer no âmbito das ciências humanas (História, Geografia, Sociologia etc.); quer no âmbito das ciências físicas e naturais (Biologia, Física, Química, Geologia etc.). O fundamental é que as conexões entre os diferentes campos do conhecimento sejam estabelecidas ${ }^{2}$ ".

Ressaltamos também que a atividade pedagógica inicial teve o intuito de ir além de um receituário, tendo em vista a busca da criação de alternativas para quebrar as amarras de rotinas no trabalho escolar.

\section{ASPECTOS DA METODOLOGIA}

Iniciamos com a atividade Variação da temperatura ambiente, cuja finalidade foi a ampliação das noções de tempo - relações entre fatos presentes, próximos e remotos - e das mudanças que ocorrem na realidade mais próxima da criança, procurando não limitar a atividade a anotações diárias sobre um calendário previamente formulado.

Foi deste subtema - a partir dos questionamentos, das hipóteseś, das dúvidas levantadas pelos alunos - que se criaram as condições para o desenvolvimento de outros tantos subtemas, tais como: variações do tempo, fases da Lua, dia e noite. O objetivo foi ampliado para o estudo do ambiente natural através da observação direta e através do acompanhamento do noticiário da imprensa sobre o tema (observação indireta). Utilizamos técnicas de pesquisas bibliográficas -

\footnotetext{
* Compreendemos as transformações e interações do ambiente nas dimensões sociais, políticas, econômicas, científicas e tecnológicas. 1. AMARAL, Ivan Morosino do. Ambiente, Educação Ambiental e Ensino de Ciências. In: Ciências na escola de $1^{\circ}$ grau: textos de apoio à proposta curricular. 2. ed. São Paulo: Secretaria da Educação/Coordenadoria de Estudos e Normas Pedagógicas, 1992. p. 45 .

2. GOUVEIA, Mariley Simões Floria. Construindo uma metodologia de Ensino de Ciências com professoras do ciclo básico. In: Ciências na escola de $1^{\circ}$ grau: textos de apoio à proposta curricular. 2. ed., São Paulo: Secretária da Educação/ Coordenadoria de Estudos e Normas Pedagógicas, 1992. p. 83.
} 
em jornais e revistas predominantemente -, de campo - coleta e análise de dados empíricos - e de opinião - consulta a familiares.

Para o desenvolvimento das atividades, foram utilizados os seguintes materiais: termômetro, tabelas mimeografadas, papel quadriculado, relógio de papel cartolina construído pelas professoras, exemplares do jornal Folha de S. Paulo, revistas, vídeo e globo terrestre.

\section{DESENVOLVIMENTO DAS ATIVIDADES}

Foi a partir dos alunos, de suas dúvidas, questões e hipóteses, que surgiram o que denominamos subtemas, e que caracterizou o estudo como um trabalho interdisciplinar, como propõe Gonçalves ${ }^{3}$. Segundo essa autora, com o trabalho interdisciplinar, as diferentes matérias escolares interagem em um processo unitário, contribuindo de forma decisiva para a aprendizagem e o desenvolvimento intelectual do aluno.

\section{Variação da temperatura}

No subtema variação da temperatura realizamos estudo diário da variação da temperatura, através da observação direta (temperatura da sala de aula) e indireta (leitura da seção Atmosfera, do caderno Cotidiano do jornal Folha de S. Paulo). Foram construídos, com dados obtidos a partir da observação direta, tabelas e gráficos.

Essa atividade desenvolvida em torno da variação da temperatura ambiente exigiu o uso do termômetro. Os termômetros utilizados foram os comumente encontrados no comércio, cujas qualidade e precisão podem ser questionadas. Assim como os outros materiais, eles também tiveram de ser adquiridos pelas professoras. A elaboração de tabelas e gráficos já era do conhecimento dos alunos, trabalhada em atividades nas disciplinas História, Geografia e Matemática.

O termômetro utilizado nessa atividade ficava na sala de aula, sempre em um mesmo lugar, afixado na parede ao lado da lousa, em uma altura onde todos os alunos pudessem observá-lo. Os dados sobre temperatura eram obtidos pela observação direta, em horário previamente estabelecido com os alunos. Nas quartas séries do ensino fundamental (período da manhã), com uma das classes o horário estabeleci- 
do foi às $7 \mathrm{~h}$ (início da aula) e com a outra às $10 \mathrm{~h}$ (após o recreio); nas terceiras séries (período da tarde) foi sempre às 13h30min (início da aula). No entanto, os alunos sempre tiveram livre acesso para verificar a temperatura durante o período de aula.

Inicialmente fizemos descrição e explicação sobre o termômetro: o que era, para que servia, como era constituído. Houve também explicações sobre: escala termométrica, o que eram os pontos fixos, número de divisões da escala, escalas Fahrenheit e Centígrada (Celsius); a escala adotada no Brasil. Os gráficos foram construídos a partir dos dados obtidos, respeitando a divisão da escala do termômetro que poderia ser tanto de um em um grau quanto de dois em dois graus.

Foram utilizados dois termômetros: o primeiro possuía as escalas termométricas centígrada e Fahrenheit e permitia a leitura de dois em dois graus ${ }^{\circ} \mathrm{C} \mathrm{e}{ }^{\circ} \mathrm{F} ; \mathrm{o}$ segundo possuía somente a escala centígrada e permitia a leitura de um em um grau ${ }^{\circ} \mathrm{C}$. A mudança foi necessária devido a quebras do material e, importante, os alunos perceberam que existem divisões diferentes entre os pontos máximo $\left(100^{\circ} \mathrm{C}\right)$ e mínimo $\left(0^{\circ} \mathrm{C}\right)$ nos vários termômetros encontrados no mercado.

A regularidade na leitura da temperatura era obtida fixando o horário de observação e designando como local a sala de aula. $\mathrm{O}$ objetivo de manter a regularidade era mostrar que na realização de experimentos é necessário garantir certas condições para controle das variáveis (clima, luminosidade, intensidade de calor, localização geográfica etc.).

Durante o período em que se desenvolveram as atividades surgiram várias perguntas ${ }^{4}$ que foram explicadas, discutidas e quando necessário alteraram aspectos da atividade. Foram questões do tipo: "Como

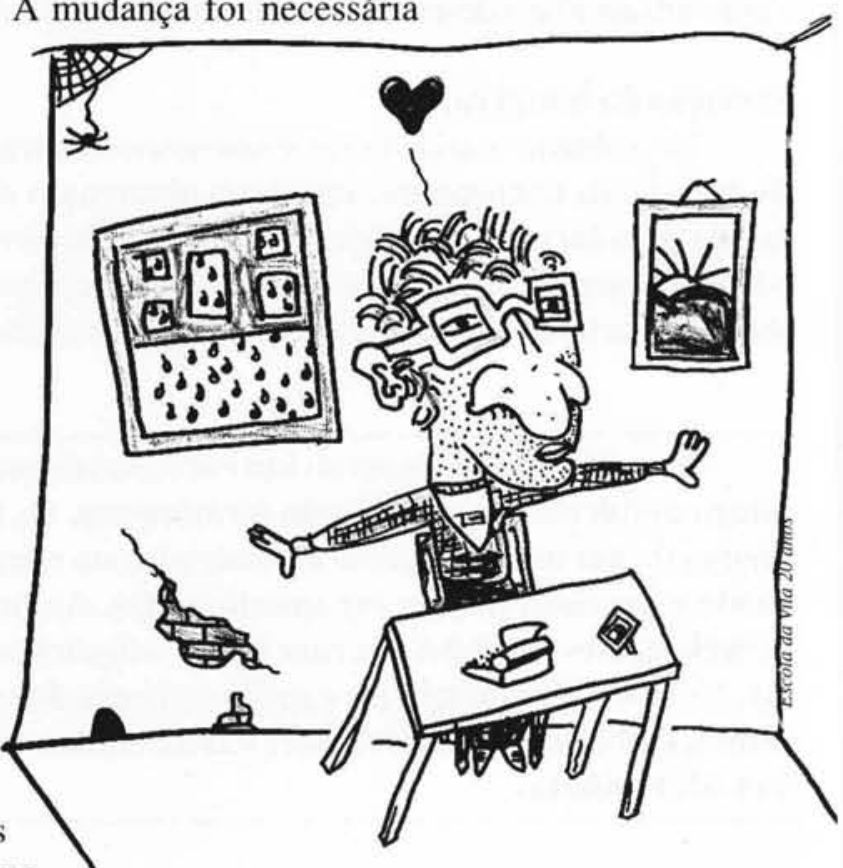
faríamos a anotação se a temperatura chegasse abaixo de zero graus?" Esta pergunta se deu porque na última semana de agosto, quando teve início a atividade, foi elaborado e distribuído para os alunos um gráfico mimeografado, no qual no eixo das ordenadas não havia possibilidade de anotar temperaturas abaixo de zero. Após conversa com a classe sobre a possibilidade de a temperatura atingir valores abaixo de zero em nossa 
região (estávamos no final do inverno), decidimos colocar valores abaixo de zero, como também utilizar papel quadriculado, o que facilitou a construção do gráfico. Outras questões surgiram: "O que aconteceria com as pessoas se a temperatura atingisse $50^{\circ} \mathrm{C}$ ou $-50^{\circ} \mathrm{C}$ ?"; "O calor do corpo humano poderia aumentar a temperatura da sala de aula?"; "Estávamos no inverno, mas por que a temperatura estava elevada?".

Todas as perguntas foram discutidas e respondidas, respeitando-se o nível de conhecimento e desenvolvimento dos alunos e, a partir delas, foi possível abordar outros conteúdos de Ciências. Estas atividades possibilitaram trabalhar, também, em Português, a produção de texto jornalístico; em Geografia, a produção de legendas e mapas; em Matemática, a elaboração do cálculo de média, porcentagem, medida de capacidade e as quatro operações.

\section{Variação do tempo}

O estudo da variação das condições atmosféricas locais iniciouse no mês de setembro, com as anotações diárias da ocorrência ou não de chuvas. Passamos, nos meses de outubro e novembro, a anotar diariamente as variações do tempo: ensolarado, nublado, chuvoso. Os alunos criaram legendas para identificar as três situações. As anotações foram em forma de tabela e houve a leitura diária da seção Atmosfera, do jornal Folha de S. Paulo. Esta seção contém informações sobre previsão de tempo/temperatura no Brasil e no Estado de São Paulo, sobre horários do nascente e poente do Sol, do início das fases da Lua, sobre marés, qualidade das praias, qualidade do ar, além de outras informações a respeito de características atmosféricas do mundo, dados que beneficiaram nosso trabalho. Qualquer outro jornal que contenha essas informações poderá ser utilizado no desenvolvimento das atividades descritas neste artigo.

No mês de setembro, como estávamos no final do inverno e no início da primavera, ocorreu um período em que o índice de umidade do ar atingiu níveis muito baixos, sendo este fato amplamente divulgado pela televisão e pelos jornais, permitindo várias discussões. Foram discutidos os problemas que a baixa umidade do ar poderia causar para os seres vivos, incluindo o homem, deixando claro, por exemplo, por que as atividades de Educação Física haviam sido suspensas. 
Foi desta atividade, ou seja, da constatação do problema da baixa umidade do ar, das temperaturas elevadas para a época do ano, feitas, principalmente, através da leitura do jornal e do noticiário da TV, que surgiu o interesse dos alunos por EI Niño. Este fenômemo provocou muitas discussões e a abordagem de vários conteúdos em Ciências e em outras áreas do conhecimento.

Os alunos passaram a trazer (a pedido das professoras) notícias de jornais sobre El Niño. Depois de explicar o que era o fenômeno e algumas de suas características, discutimos a razão de seu nome. $\mathrm{O}$ assunto despertou muito interesse principalmente sobre as consequiências que o fenômeno poderia provocar, tais como período de secas ou inundações. Nas terceiras séries, passamos a discutir os problemas que o fenômeno poderia causar para a agricultura, incluindo a possibilidade de haver escassez de alimentos. Essa problematização nos fez discutir as conseqüências sociais de tal fenômeno, levando-nos a questões, por exemplo, sobre qual classe social poderia passar fome caso El Niño provocasse quebras drásticas na agricultura. Foi possível também interligar essas discussões e informações com o tema trabalho. Essa temática vinha sendo discutida em História, a partir de dados sobre a exploração do trabalho infantil e da problemática dos sem-terra.

Nas quartas séries, a partir da leitura da seção Atmosfera, do jornal Folha de S. Paulo, ficamos informados sobre o que estava acontecendo em diversas partes da Terra. Um aluno fez a pergunta: "Por que no Brasil não temos neve"? Dessa conversa surgiram outras perguntas como: "Por que, com tanta água que temos no planeta, falta água na torneira de minha casa"?

Tivemos um diálogo sobre as reservas naturais de água potável. Esclarecemos que estas reservas não são inesgotáveis e que poderemos ter problemas graves de es-

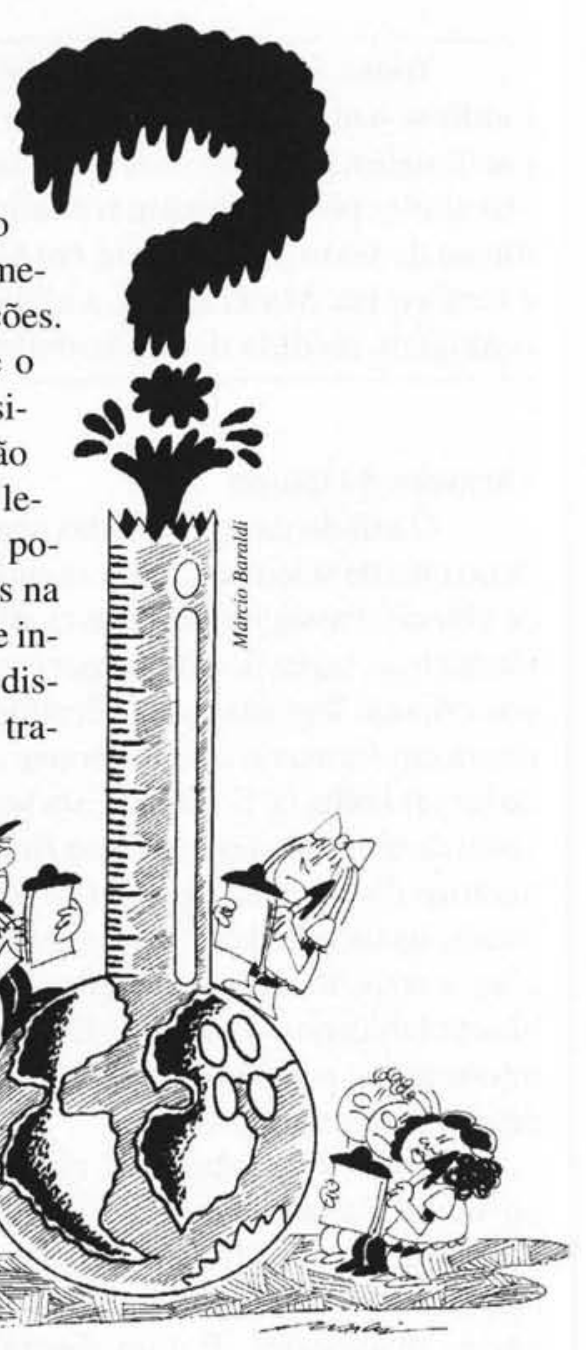
cassez caso continue o uso descontrolado.

Exibimos um filme sobre o desperdício de água (da série Castelo Rá-Tim-Bum), depois disso, passamos a trabalhar com o livro de literatura infantil Aventuras de uma gota d'água ${ }^{5}$. As infomações obtidas tanto no filme quanto no livro nos permitiram a abordagem dos 
seguintes assuntos: o uso doméstico de água, ciclo da água, a importância da água para a vida do homem, formação de nuvens, gotas, evaporação, infiltração, córregos, rios e mares, a ingratidão do homem quando este polui as águas.

Em Matemática, pudemos abordar noções de porcentagem, medidas de capacidade e as quatro operações.

Exploramos também dois artigos extraídos do jornal Folha de S. Paulo, um de 9 de novembro de 1993, Água deve faltar para 3 bilhões até o ano 2.025, e outro, de 19 de novembro de 1997, Venda de água vira bom negócio na Paraíba; este último abordava a venda de um galão de água potável a $R \$ 1,00$ e o galão de água suja a $R \$ 0,50$.

\section{Fases da Lua}

O subtema fases da Lua teve sua origem a partir de uma pergunta de um aluno da quarta série: "Por que algumas vezes durante o dia podemos ver a Lua e durante a noite não vemos o Sol?" Para seu estudo, voltamos a utilizar informações de jornal. A partir dos dados sobre o horário do início das fases da lua foram construídas duas tabelas. Na primeira, elaborada no mês de setembro, havia colunas com informações obtidas a partir do jornal, da observação em casa e na escola; nela, os alunos deveriam anotar o horário e a forma da Lua que observaram ou se não observaram. No segundo mês, outubro, introduziu-se mais uma coluna onde o aluno deveria anotar se eram as condições do tempo que não permitiam a observação ou, então, qual o motivo de não haver observação. Utilizamos, nesse segundo mês, um cartaz feito a partir de uma propaganda publicada em revistas que trazia fotos das mudanças de fases da Lua.

Os alunos fizeram observações muito interessantes. Primeiramente, procuravam a Lua no céu em todas as direções e depois de algum tempo já sabiam a direção da trajetória da Lua. Puderam perceber que na representação do jornal (através das legendas) não havia mudanças, mas em suas observações a Lua mudava de forma diariamente, havendo a necessidade de explicação sobre a questão: "Por que a representação da Lua era padronizada no jornal e variável na natureza?".

Da observação da Lua na escola e em casa, surgiram perguntas como: "O que são as diferentes tonalidades da superfície da Lua?", 
“O dragão de São Jorge mora lá?”, “A professora viu o nariz da Lua?”, "A minha avó disse que não estamos vendo a Lua na fase nova, porque ela só pode ser vista no terceiro dia", fato que foi confirmado pela observação da classe, como também foi confirmada junto a um cabeleireiro a crença da relação do corte de cabelo com cada fase da Lua. "Na Lua cheia as pessoas se transformam em lobisomem?" esse assunto foi muito discutido em sala por causa da novela que estava passando na TV.

Da mesma maneira, a veracidade do jornal e o conhecimento popular foram contestados, o que mostra dois aspectos interessantes em relação à crença. Ela é chamada para justificar um argumento que faz parte do senso comum e pode ser submetida a um teste de veracidade, como escreve Matallo ${ }^{6}$. Ela é uma forma de conhecimento que tem uma longa duração na sociedade humana. Por outro lado, não é comum, particularmente na escola, testar ou questionar a veracidade do conhecimento científico, apenas demonstrá-la.

\section{Dia e Noite}

A diferença na duração dos dias foi registrada através da construção de uma tabela com anotações diárias do horário do Sol nascente e poente. $\mathrm{O}$ horário era registrado tendo como base os dados fornecidos pela seção Atmosfera do jornal Folha de S. Paulo. Foi esta atividade que permitiu a abordagem dos seguintes conteúdos escolares: medidas padronizadas de tempo - hora e minuto; diferenças na duração dos dias; ocorrência do movimento aparente do Sol. A utilização do jornal permitiu interação entre as várias áreas do conhecimento como História, Geografia e Matemática.

A regularidade das variações da duração do dia através de anotações do horário do Sol nascente e poente foi observada pelos alunos em falas como: "Muda de um em um minuto". "Muda de dois em dois minutos". A observação - dos dados recolhidos diretamente do ambiente, comparando-os com os publicados no jornal conduziu a interessantes conclusões com relação à aproximação ou ao distanciamento entre essas duas fontes de dados sobre os fenômenos dia/noite.

Da observação do horário do Sol poente, foi possível explicar para os alunos das terceiras séries o que queria dizer horizonte, palavra da qual os alunos desconheciam o significado. Após a explicação do significado, um aluno de uma das turmas fez uma afirmação que produziu uma discussão entre seus colegas de classe: "Se eu caminhar até 
o horizonte vou tocar no céu?" Esta afirmação gerou uma discussão entre os alunos quando eles formularam várias hipóteses e ainda continuaram com idéias diferentes. Foi importante para os alunos pois não representou uma questão comprovada, fechada. Ficou em aberto, à guisa de novas respostas.

\section{DESAFIOS DA INTERDISCIPLINARIDADE}

Preocupadas em não transmitir conhecimentos prontos e acabados, desvinculados da realidade, criamos uma situação pedagógica sobre o estudo da variação da temperatura ambiente, onde os conteúdos foram extraídos do cotidiano do aluno e na qual houve um trabalho conjunto com a participação do professor e do aluno através de diálogo, discussões, dúvidas, investigação e criatividade.

O conhecimento do aluno foi ponto de partida para uma discussão do conhecimento científico. Esse conhecimento foi utilizado para interpretar fatos rotineiros da realidade, respeitando o desenvolvimento intelectual dos alunos, de maneira que provocassem comparações entre eles, permitindo que avaliassem as vantagens e desvantagens do conhecimento científico, tecnológico e seus respectivos papéis na sociedade moderna.

Esta situação pedagógica permitiu desenvolvermos outros conteúdos na área de Ciências Físicas e Naturais, em uma perspectiva interdisciplinar.

$\mathrm{O}$ estudo da variação da temperatura ambiente, um subtema do tema $o$ ambiente, permitiu a abordagem interdisciplinar porque entendemos que a noção de ambiente é construída a partir da apreensão de seus componentes, de seus processos e de suas múltiplas relações, nos aspectos físicos, químicos, geológicos, biológicos, tecnológicos e socioeconômicoculturais. Essa abordagem permite que se criem condições para que $o$ aluno comece a questionar e compreender as decisões de ordem política, social e econômica, como é apontado na Proposta Curricular para o ensino de Ciências em São Paulo. Em determinados casos, conseguimos fazer estes tipos de associação. Por exemplo, quando foi abordada a reportagem sobre a venda de água, ou o problema que o fenômeno El Niño causaria se houvesse seca e fome, perguntou-se quem seriam as vítimas? Ambas envolvem questões políticas, sociais e éticas. 
Porém, esta proposta de trabalho foi limitada pelo tempo disponível para realizá-la. O subtema variação da temperatura, como gerador de outros conteúdos e interdisciplinaridade, deve ser trabalhado em pelo menos duas estações do ano, como sugestão para o desenvolvimento do tema $o$ ambiente.

Dada a importância que o tema ambiente tem em nossa sociedade, fazendo parte, inclusive, de um dos temas transversais dos Novos Parâmetros Curriculares Nacionais (1997), sugerimos que ele seja abordado de acordo com a Proposta Curricular para o ensino de Ciências e programas de saúde do primeiro grau da Secretaria do Estado de São Paulo em sua versão de $1988^{7}$.

Ressaltamos que a questão da interdisciplinaridade abordada por nós foi uma tentativa de melhor compreendê-la, pois entendemos que não se faz a interdisciplinaridade, mas deve-se ser interdisciplinar. E como alunas/professoras em processo de nos tornarmos interdisciplinares, sabemos que existe um caminho a percorrer para melhor compreendê-la.

Assim, propomos que, em qualquer atividade pedagógica a ser desenvolvida, a interdisciplinaridade deva estar presente tendo em mente o que escreve Freitas: "Interdisciplinaridade é entendida como interpenetração de método e conteúdo entre disciplinas que se dispõem a trabalhar conjuntamente um determinado objeto de estudo"8. Hoje a tentativa de criar possibilidades para desenvolvê-la deve também ter em conta que "(...) longe de desacreditar a interdisciplinaridade no atual quadro do desenvolvimento científico, ela deve ser mais uma bandeira de luta" .

No nosso trabalho docente, ligar os diferentes tipos de conhecimento com a produção científica é fundamental para entender também nossa própria produção de conhecimento. Trabalhando com a produção científica, nós, professores, devemos nos colocar como professores pesquisadores, ou seja, aqueles que estão no movimento de ação/reflexão/ação, pesquisando a sua própria prática pedagógica e tendo uma relação dialógica com os alunos.

Consideramos, inclusive, essa postura como condição necessária para o desenvolvimento de uma prática pedagógica interdisciplinar.

Ressaltamos também que, para que haja mudanças na prática pedagógica dos professores, outras condições são necessárias e importan-

7. SÃO PAULO (Estado) Secretaria da Educação. Coordenadoria de Estudos e Normas Pedagógicas. Proposta curricular para o ensino de Ciências e programas de saúde. Primeiro grau. 3. ed. São Paulo: 1988.

8. FREITAS, Luís Carlos de. Crítica da organização do trabalho pedagógico e da didática. Campinas,. São Paulo: Papirus, 1995. p. 91.

9. FREITAS, Luís Carlos de. Crítica... op. cit. p. 91. 
tes, como a interação com as Universidades, o trabalho coletivo, espaços para troca de experiências e condições materiais. Dentre estes, no nosso caso, o determinante foi a vontade política e uma maior interação entre a escola pública de ensino fundamental e a Faculdade de Educação da Universidade de Campinas. Agradecemos especialmente a professora Mariley Simões Flória Gouveia pela amizade e orientação durante o curso de Especialização em Avaliação, que resultaram em apoio e incentivo para que fizéssemos este relato de nossa prática pedagógica. Cabe aqui também agradecer ao professor Antônio Carlos Rodrigues Amorim, por sua orientação, revisão e estímulo na elaboração do artigo.

Resumo: As autoras relatam experiência interdisciplinar no ensino de ciências com alunos de terceira e quarta séries do ensino fundamental em escola pública do Estado de São Paulo. Elas partem do estudo do tema 0 ambiente para observar a variação da temperatura, a variação do tempo e as fases da Lua, apoiadas na coleta de dados, a partir da medição científica, da leitura de jornal, livro e da observação direta do meio ambiente. A análise dos dados permite relações entre as diferentes áreas do conhecimento: Português, Matemática, História e Geografia. Possibilita também um aprendizado rico, dinâmico que valoriza o conhecimento do aluno, levando-o à construção do conhecimento científico.

Palavras-chave: interdisciplinar, ensino de Ciências, ambiente, ensino fundamental, jornal, meios de comunicação
Abstract: The authors report on an interdisciplinary experience in teaching science carried out with third and fourth grade students in a public school in the State of São Paulo. They begin studying the environmental theme observing variations in temperature, in the weather and in moon phases, supported by data collection, based on scientific measurement, newspaper and book reading and on direct observation of the environment. Data analysis allows for relations to be made between different areas of knowledge such as Portuguese, mathematics, history and geography. It also allows for a rich and dynamic learning process, which values student knowledge and leads to scientific knowledge.

Key words: interdisciplinary, Science teaching, environment, elementary teaching, newspaper, means of communication 